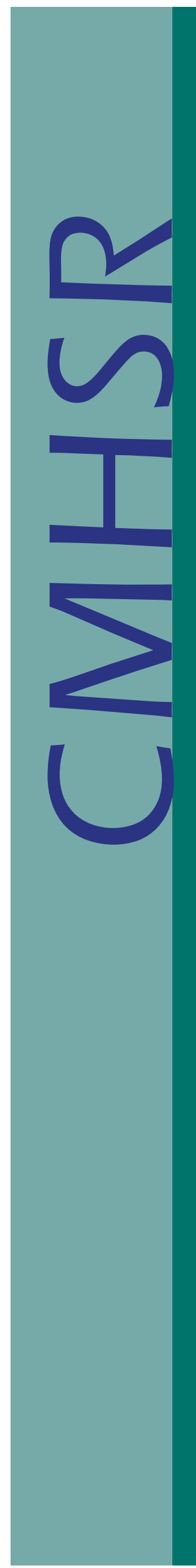

October 2004

Vol 1, Issue 8

\title{
Crisis Intervention \& Risk Management Training for Police: De-Escalating Offenders in Crisis While Maintaining Public Safety
}

Jonathan C. Clayfield, MA, Albert J. Grudzinskas, Jr., J.D., Hon. Maurice H. Richardson, William H. Fisher, Ph.D., and Kristen Roy-Bujnowski, MA

$\mathrm{P}$ olice are often the first responders when crisis situations arise. They are expected to be able to deal with a myriad of unknowns when they respond to a call. Police are trained to take command of situations and subdue offenders, using a combination of nonlethal and, less frequently, lethal force. Their first priority is public safety. When police are faced with individuals in crisis - often referred to as emotionally disturbed persons or EDPs by police - such non-lethal and lethal means of force frequently lead to an escalation in crisis behavior by the offender. This type of response can often result in injuries, and in some instances even death, to the offender as well as to the officer responding to the call.

\section{Violence and Mental IIIness}

Despite recent research findings to the contrary, the stigma of the mentally ill as violent individuals still persists, as evidenced in the way in which they are portrayed in the movies and in other media. Studies suggest that persons with mental illness are no more violent than persons without a mental illness. ${ }^{1}$ Substance abuse, however, does appear to be a factor in predicting whether a person will behave violently. "Drug and alcohol abuse can often trigger drug-induced psychosis, suicidal thoughts and other anti-social and violent behavior. Proper preparation and training is the key factor in successfully dealing with disturbed individuals so these situations don't escalate into personnel complaints,

(C) 2004 Center for Mental Health Services Research Department of Psychiatry

UMASS. University of Massachusetts Medical School excessive force or suicide by cop."2 When police confront an EDP and there is evidence at the scene that the offender has been abusing drugs or alcohol, there is a much higher potential risk of violence. However, mentally ill offenders who are violent are more likely to attack a relative or family member, most often a caretaker, while strangers or people outside the mentally ill person's social network are rarely targets of violence. ${ }^{3}$

\section{Mental Health Training Approaches}

Many law enforcement officials across the country have recognized the need for special training to deal more effectively with EDPs. One of the more well-known training approaches is the Memphis Crisis Intervention Team (CIT) Training Model. This approach helps police departments develop a specialized unit consisting of a cadre of officers who receive forty (40) hours of crisis intervention training. While these CIT units have helped many departments deal more effectively with EDP calls and reduce injuries to offenders and officers, this model does not seem feasible for police departments of large urban areas, such as New York City, which averages an EDP call every 7.3 minutes. ${ }^{4}$ In addition, many police unions require departments to pay officers who have received specialized training more money, an unrealistic option for departments faced with reduced budgets, scarce resources, and personnel layoffs.

In response to these concerns, the Massachusetts Mental Health Diversion \& Integration Program 
(MMHDIP) of the University of Massachusetts Medical School has developed a sixteen (16) hour Crisis Intervention and Risk Management (CIRM) training curriculum. This training has been delivered successfully to the Worcester and Boston Police Academies over the past several years. The CIRM training focuses on recognizing the signs and symptoms of mental illness, learning how to de-escalate crisis situations, and understanding what community resource options exist for police officers who wish to seek treatment for an EDP in lieu of arrest. A pilot version of this curriculum was recently delivered as part of the Worcester Police Department in-service training in 2002, where the entire police department from the Police Chief to the civilian dispatchers (over 440 personnel) was trained. The CIRM curriculum focuses on public safety first, emphasizing to the officers that if they get injured or incapacitated, everyone else at the scene, including the individual in crisis, is at increased risk of harm. Some of the key features of this training curriculum include:

- Emphasis on importance of the officers' public safety role.

- Prevalence data/statistics on mental illness.

- Differences between mental illness and mental retardation.

- Relevant aspects of Massachusetts General Law, Chapter 123. (commitment law)

- Recognizing the signs \& symptoms of mental illness (NOT diagnosis).

- The do's and don'ts when interacting with individuals in crisis (de-escalation techniques).

- Community-based treatment resources that officers can access in lieu of arrest.

- Consumer perspectives on living with a mental illness.

\section{Mental Health Consumer Involvement}

Both the CIT and MMHDIP trainings rely heavily on consumer involvement, from the planning stages to the delivery of the training curriculum. From feedback the MMHDIP has received from the Boston and Worcester Police Academy recruits, the "consumer perspectives"

Visit us on-line at www.umassmed.edu/cmhsr piece of the CIRM training has had the biggest impact. In particular, officers noted that having consumers share their experiences of having a mental illness was helpful in dispelling myths and stigma about persons with mental illness, and in providing a context for the information presented during the training.

\section{Future Policy Considerations}

Given the general lack of, and recent cuts in, funding for outpatient mental health and substance abuse services that plague towns and cities throughout the U.S., police have become the de facto service provider of first, and last, resort. Despite the acknowledgement and, based on our experience working with the police departments in the two largest Massachusetts cities, the acceptance of this service provider role, very little training is provided to prepare officers to deal with persons in crisis.

Although the Memphis CIT police training model has had success and wide-spread replication in many jurisdictions across the country, many police departments find this model to be impractical because they face budget cutbacks, union issues, and/or average a large volume of EDP calls on a daily basis. In response to these issues, training all officers has proven to be an effective alternative.

References
1. Monahan, J., Steadman, H., Silver, E., Appelbaum, P., Robbins, P., Mulvey, E.,
Roth, L., Grisso, T., \& Banks, S. (2001). Rethinking Risk Assessment: The
MacArthur Study of Mental Disorder and Violence. New York, NY: Oxford
University Press, Inc.
Bellah, J. (April, 2002). Recognizing Mental Illness. Retrieved from
http://www.hendonpub.com/LawMag/catalog.cfm? dest=item
pg\&itemid=6679\&linkon=category\&linkid=84\&secid=15 on June 28, 2004.
American Psychiatric Association. (January, 1998). Fact Sheet Series: Violence
and Mental Illness. Retrieved from http://www. sych.org/public_info/violence.pdf
on September 13, 2004.

For more information on the Massachusetts Mental Health Diversion \& Integration Program's Crisis Intervention \& Risk Management (CIRM) training for police officers, please email the authors at diversion@umassmed.edu 